\title{
LLNL-TR-640610
}

LAWRENCE LIVERMORE NATIONAL LABORATORY

\section{Improvised Nuclear Device Technical Basis CalEMA RNER Framework Supplement}

\author{
B. R. Buddemeier \\ D. L. Stewart \\ J. E. Valentine
}

\author{
Lawrence Livermore National Laboratory \\ Lawrence Livermore National Laboratory \\ Lawrence Livermore National Laboratory
}

\section{June 2013}

This work was performed under the auspices of the U.S. Department of Energy by Lawrence Livermore National Laboratory under Contract DE-AC52-07NA27344.

This document was prepared as an account of work sponsored by an agency of the United States government. Neither the United States government nor Lawrence Livermore National Security, LLC, nor any of their employees makes any warranty, expressed or implied, or assumes any legal liability or responsibility for the accuracy, completeness, or usefulness of any information, apparatus, product, or process disclosed, or represents that its use would not infringe privately owned rights. Reference herein to any specific commercial product, process, or service by trade name, trademark, manufacturer, or otherwise does not necessarily constitute or imply its endorsement, recommendation, or favoring by the United States government or Lawrence Livermore National Security, LLC. The views and opinions of authors expressed herein do not necessarily state or reflect those of the United States government or Lawrence Livermore National Security, LLC, and shall not be used for advertising or product endorsement purposes. 


\section{Improvised Nuclear Device Technical Basis}

\section{Contents}

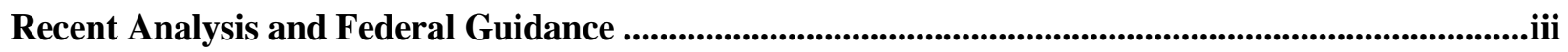

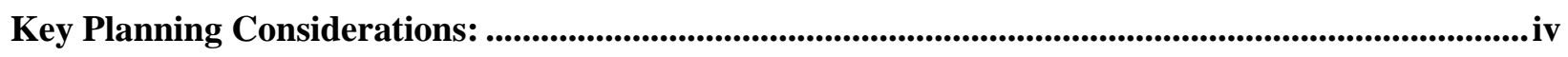

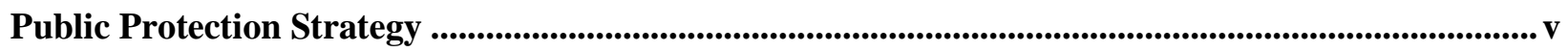

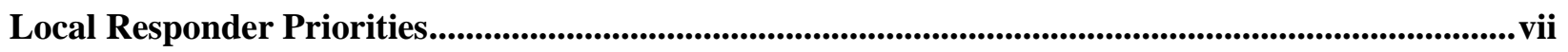

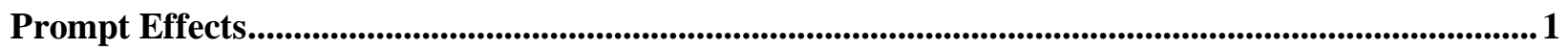

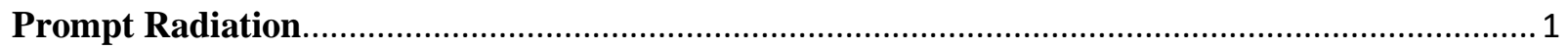

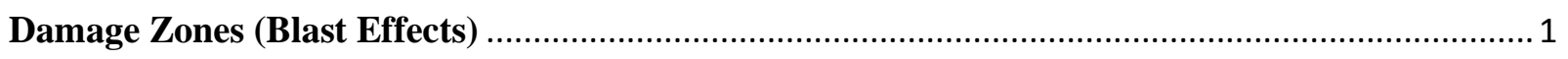

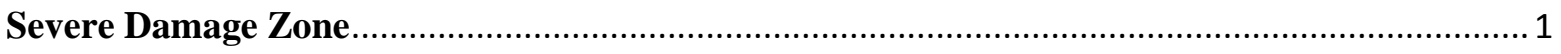

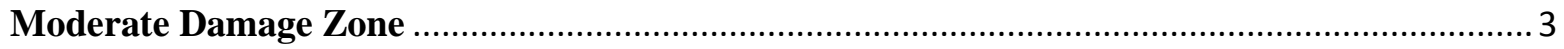

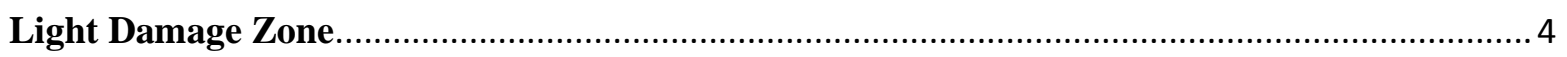

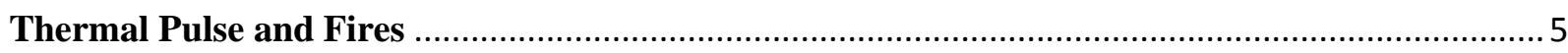

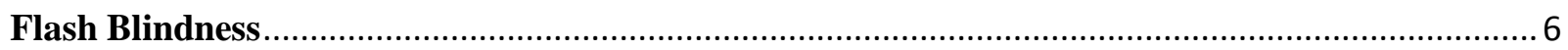

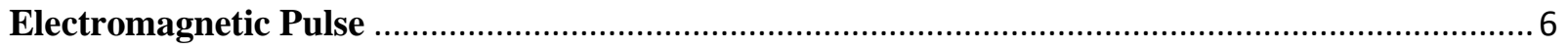

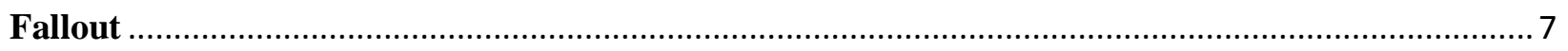

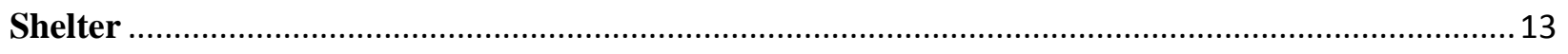

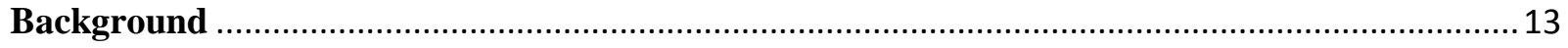

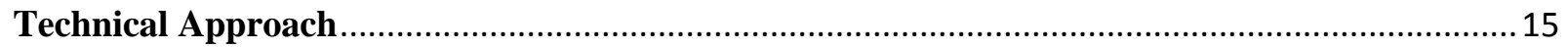

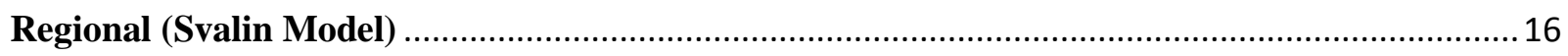

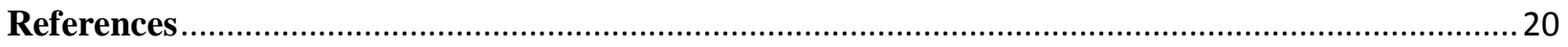




\section{Executive Summary}

\section{Recent Analysis and Federal Guidance}

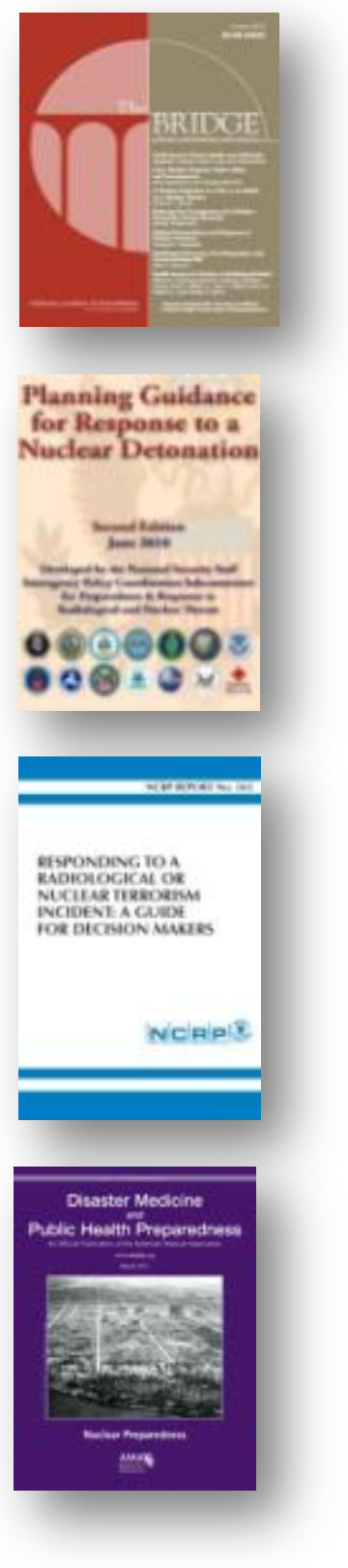

Recent research over the last few years has helped greatly improve our understanding of appropriate actions for the public and responder community to take after a nuclear detonation. Much of this research was recently highlighted in a National Academies Bridge Journal on Nuclear Dangers. This research points out the potentially misleading shelter / evacuation conclusions that can be drawn from using oversimplified modeling assumptions (a.k.a circles of prompt effects and cigar shaped Gaussian fallout patters using surface wind conditions).

Planning Guidance for Response to a Nuclear Detonation was developed by the Homeland Security Council, $2^{\text {nd }} E d$, June 2010. This interagency consensus document provides excellent background information on the effects of a nuclear detonation and key response recommendations. Its definition of zones (damage and fallout) are becoming the standard for response planning and should be integrated in the planning process.

National Council on Radiation Protection and Measurement (NCRP) Report No. 165 Responding to a Radiological or Nuclear Terrorism Incident: A Guide for Decision Makers, was released Feb 2011 and is a National Standard that supplies the science and builds on many of the concepts of the Planning Guidance.

An entire edition of the journal for Disaster Medicine and Public Health Preparedness was dedicated to the public health issues associated with the aftermath of nuclear terrorism. All of the articles are available for free download from the highlighted link.

DHS Strategy for Improving the National Response and Recovery from an IND Attack, April 2010, is an Official Use Only document that breaks the initially overwhelming IND response planning activity down into 7 manageable capability categories with supporting objectives. This can be a valuable document to guide a state and regional planning process through time phased capability requirements for Doctrine/Plans, Organization, Training, Materiel, Leadership, Personnel, Facilities, and Regulations/Authorities/Grants/Standards. This OUO document is available on LLIS.

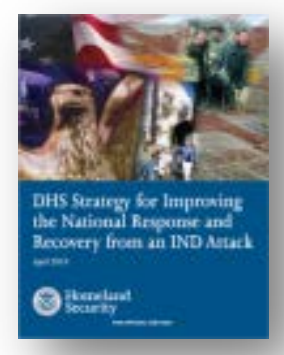




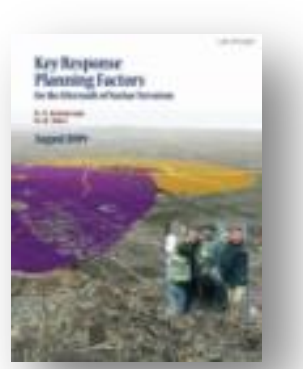

Key Response Planning Factors for the Aftermath of Nuclear Terrorism was developed by Lawrence Livermore National Laboratory in support of the DHS preparedness activity and released in August 2009. The report reviews the science behind many of the recommendations noted in the video and above doctrine.

$\underline{\text { UPMC's Center for Biosecurity's Rad Resilient Cities Project }}$

\section{Key Planning Considerations:}

It will be difficult to predict or avoid unsafe fallout areas

- The fallout cloud can go several miles up into the atmosphere and be carried in several different directions simultaneously by winds aloft.

- Fallout particles can change directions as they fall to the earth, resulting in contamination in areas other than the cloud top would indicate.

- Upper atmospheric winds often travel at high speeds (>50 mph) and it would be difficult to "outrun" the fallout cloud.

Early fallout exposure avoidance is critical; don't be outdoors when fallout arrives

- The most significant exposures from fallout occur in the first hour after fallout arrives.

- Hazardous levels of fallout are visible as it falls, seek shelter immediately if sand, ash, or rain starts to fall.

- Except in areas of major building damage, fallout should take at least several minutes to arrive.

The primary avoidable radiation hazard is external exposure to fallout

- Fallout particles on the ground and other horizontal surfaces give off penetrating radiation, inhalation is a minor concern.

- Shielding by heavy materials (i.e., concrete walls, earth, etc) and distance from the particles on the ground are the primary sources of protection.

- Being in the middle or basement of a building provides the best protection.

- Even with broken windows, buildings can provide adequate shelter.

There will be areas of blast damage that are NOT contaminated with fallout

- Blast damage extends outward from the detonation in all directions, perhaps for miles

- Fallout proceeds downwind, contaminating only a fraction of the blast damaged area 


\section{Hazardous levels of fallout will extend into undamaged downwind areas}

- Levels of fallout that can induce sickness from an outdoor exposure may extend 20 miles or more downwind

- Protective actions against fallout are warranted even if you are not in blast damaged areas

\section{A "mushroom shaped cloud" may not be generated or visible}

- Low yield, ground detonations in an urban environment may generate a non-uniform, chaotic cloud shape.

- High wind shear may quickly move the cloud in several different directions.

- Blast effects can cloud the air and limit visibility within a few miles of the detonation point.

- Nighttime or overcast skies can obscure the view of the cloud formation and movement.

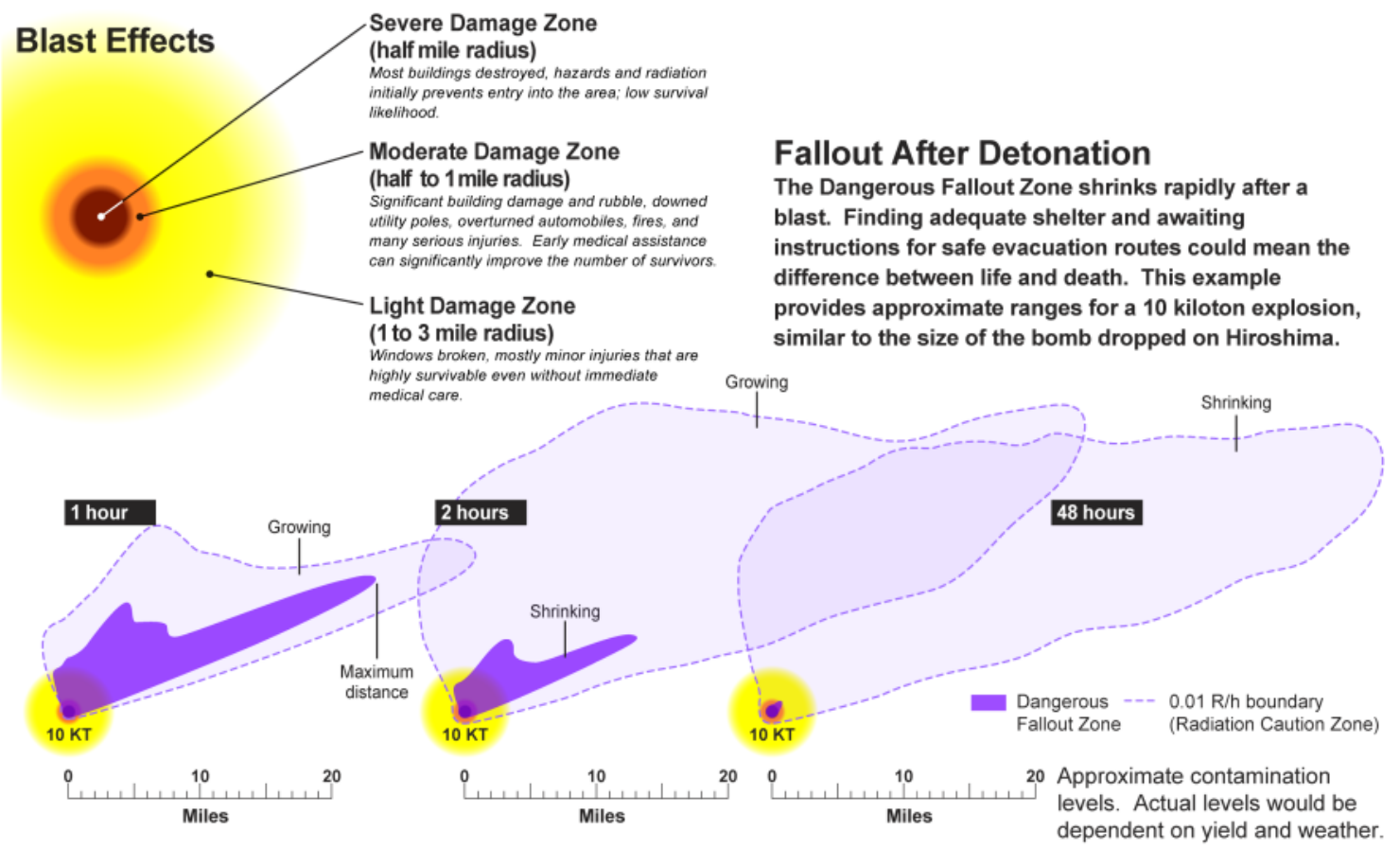

Public Protection Strategy: Early, adequate shelter followed by informed evacuation

Find Early, Adequate Shelter

- It is important to be in the shelter when the fallout arrives.

- Fallout arrival times vary with yield and weather, but if you are outside of the building collapse area, you should have at least several minutes before fallout arrives.

- If you are outside or in a car, seek the nearest adequate shelter.

- If you are already in an adequate shelter, shelter in place. 
- Adequate Shelters are locations that place as much earth, building materials, or distance between the occupants and exposed horizontal surfaces that will accumulate fallout as possible. A protection Factor (PF) of 10 or more is considered adequate. ${ }^{1}$

- Note: Buildings do not have to be "air tight," as a building with broken windows does not greatly reduce the protection offered.

\section{Perform I nformed Evacuation}

- Shelter for at least the first hour unless threatened by fire, building collapse, medical necessity, or any other immediate safety threats.

- Identify the shortest possible evacuation routes that avoid high levels of contamination.

- When feasible, consider tunnels, building lobbies, or other evacuation routes protected by earth, heavy building materials and/or distance from fallout.

- Impacted populations can be directed to local collection points (with adequate shelter) for evacuation by mass transit (i.e., busses, subways, or trains).

- Driving can be considered if the roads have been cleared and the number of evacuees can be accommodated.

- When to evacuate a shelter depends on:

o the quality of the shelter,

o radiation levels at the shelter site,

o radiation levels and travel time along the evacuation route

- Early evacuation priorities - plan for the first few hours after detonation, includes impacted populations who are:

o threatened by fire or toxic materials,

0 in danger of building collapse,

0 in inadequate shelters, or

0 in need of immediate medical attention.

- Secondary evacuation priorities - plan for the first day after detonation, includes impacted populations who are:

0 in danger from hot or cold weather,

- not in fallout areas, provided their evacuation does not hamper emergency response operations or take them through fallout areas,

0 in need of access to constant or consistent medical care (i.e. those requiring dialysis, oxygen, prescription medication, etc..), or

0 without drinking water.

\footnotetext{
${ }^{1}$ Homeland Security Council Interagency Policy Coordination subcommittee for Preparedness \& Response to Radiological and Nuclear Threats, Planning Guidance for Response to a Nuclear Detonation, Office of Science and Technology Policy, Executive Office of the President (www.ostp.gov), June, 2010.
} 


\section{Local Responder Priorities:}

Protect response personnel, regional situational assessment, and support public safety.

\section{Protect response personnel}

- Responders without radiation detection instruments: Follow the general public protection strategy.

- Responders with radiation instruments: Shelter using radiation detection equipment to monitor shelter conditions.

o Do not exit shelter or enter areas if radiation levels exceed $10 \mathrm{R} / \mathrm{hr}$ unless there is a time critical life safety issue (e.g., avoiding fire or building collapse).

o Provided outdoor radiation levels are below 10R/hr, perform scene assessment of the immediate area for hazards. Make sure to stay close to adequate shelter locations, closely monitor radiation levels, and immediately shelter if radiation levels increase rapidly.

- Personal protection considerations while working in fallout contaminations areas include:

o SCBAs, Respirators, Firefighter "turnouts", Level A, B, or C HAZMAT suits do not protect against the primary hazard - the penetrating gamma radiation given off by fallout.

o Inhalation \& ingestion is a secondary concern compared to the external exposure.

o Reducing the time spent in high dose-rate areas is the greatest protective measure. Bulky isolation suits and elaborate respiratory protection methods may actually increase exposure as they reduce the speed, the ability to communicate, and worker efficiency.

\section{Support regional situational assessment}

- Designate a regional situational assessment center that will collect information from observations, instrument readings, and weather. The identification of areas that have or are likely to receive hazardous fallout as well as those likely to remain unaffected is a high priority.

- Establish communication with responders in the affected area. Radios outside of the major building damage area should still function, although repeater towers may have been affected. Use alternate communication methods if needed.

- Report approximate radiation levels in the area. Radiation readings will change rapidly with time. Use the NCRP recommended ${ }^{2}$ boundaries of $10 \mathrm{mR} / \mathrm{hr}$ and $10 \mathrm{R} / \mathrm{hr}$ to determine low and high hazards zones.

- Local responders should record and report radiation levels and the times they were taken at regular intervals.

o Identification of high hazard zones (reading greater than $10 \mathrm{R} / \mathrm{hr}$ ) is a priority, but reporting safe areas (reading less than $10 \mathrm{mR} / \mathrm{hr}$ ) is also important for the determination of safe evacuation routes and response staging areas.

\footnotetext{
${ }^{2}$ NCRP (2005). National Council on Radiation Protection and Measurements. "Key Elements of Preparing Emergency Responders for Nuclear and Radiological Terrorism," Commentary No. 19 (National Council on Radiation Protection and Measurements, Bethesda, MD)
} 


\section{Support Public Safety}

- For a suspected nuclear detonation, use all available communication and emergency alert systems to immediately broadcast shelter instructions.

- Establish safe evacuation routes from high hazard areas and identify evacuation priorities.

- Provide local public safety support including setting up and directing general public to adequately sheltered triage sites.

- Fight fires. The detonation will cause fires in the area where populations are sheltered. Take action to slow the spread of fire.

- Establish triage, decontamination, and casualty collection points outside of hazardous fallout zones. 


\section{Prompt Effects}

"Prompt" effects are those that radiate outward from a detonation location (ground zero) usually in the first minute. Such effects include the intense flash of light, blast shockwave, heat, and prompt radiation. Using state-of-the-art assessments of these effects, we find that not only our instincts but also our traditional modeling predictions are incorrect for a detonation in an urban area. Urban terrain will significantly perturb the range of damage due to blast effects, and buildings will reduce the overall extent of the thermal and ionizing radiation impacts. Each of these effects is examined and compared with respect to the nominal range of the Severe, Moderate and Light damage zones. In similar fashion to IND response planning guidance, "fuzzy circles" are used to describe the zones ((EOP, 2010), due to the variability in the contours (overpressure, radiation level and thermal fluence) caused by the urban terrain.

\section{Prompt Radiation}

Relatively open areas do not exhibit a significant reduction in exposure. Built-up areas would protect the outdoor population and reduce outdoor radiation exposure significantly when compared with the predicted open-field exposure traditionally reported in models.

\section{Damage Zones (Blast Effects)}

When assessing the best course of action to take following a nuclear detonation, decision-makers should consider using the three major blast-damage zones recommended by the Federal document, Planning Guidance for Response to a Nuclear Detonation (EOP, 2010). The three zones are:

- Severe Damage Zone (SDZ).

- Moderate Damage Zone (MDZ).

- $\quad$ Light Damage Zone (LDZ).

These three damage zones are determined by the amounts of observable damage from blast effects; this visual evidence is the simplest way for responders to understand what to expect in each zone (Figure 1). This information will help determine the most appropriate actions for both responder safety and mission support.

\section{Severe Damage Zone}

The Severe Damage Zone (SDZ) is the area that immediately surrounds a detonation site and extends to $\sim 0.5$ mile radius for a 10-kT explosion. In the SDZ, few, if any, above-ground buildings are expected to remain structurally sound or even standing, and few people would survive; however, some people protected within stable structures (e.g., subterranean parking garages or subway tunnels) at the time of the explosion could survive the initial blast. However very high radiation levels and other hazards are expected to persist in the SDZ making the zone gravely dangerous to survivors and responders. The SDZ should be considered a "No-Go" zone during the early days following an explosion. 


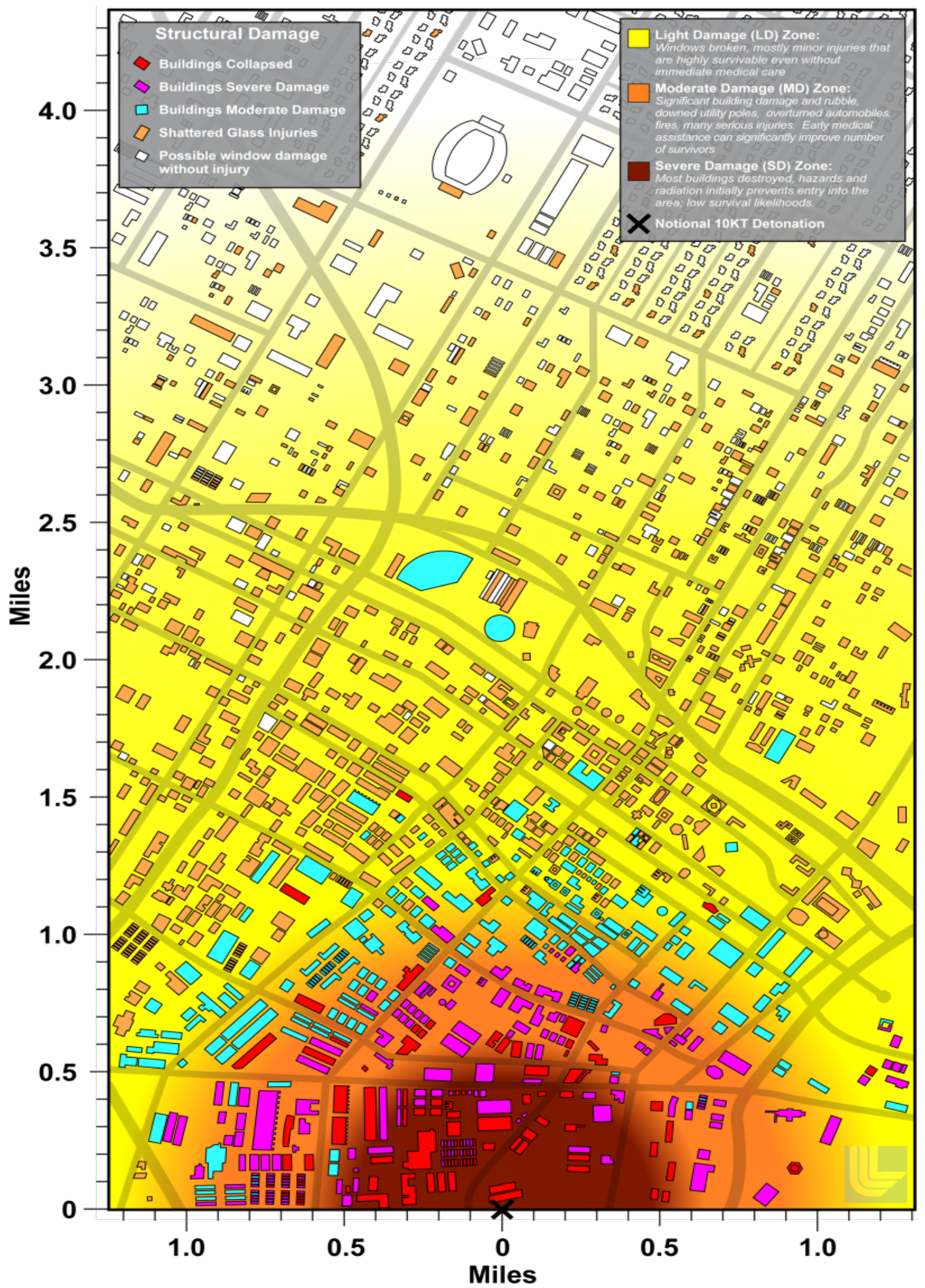

Figure 1: Damage Zones and associated Blast Effects from a 10-kT type device 
The shockwave movement underground also damages tunnels and underground infrastructure, such as water mains, power, telecommunications, and gas conduits. This underground damage area is limited to within a few hundred yards of the detonation site, well within the SDZ, but the impact to the infrastructure could have cascading repercussions outside of the SDZ.

\section{Moderate Damage Zone}

The Moderate Damage Zone (MDZ) is the area adjacent to the SDZ that extends to a distance of about 1 mile from ground zero for a 10-kT detonation. Visual indicators describing the MDZ include:

- $\quad$ Significant structural damage.

- Blown out building interiors.

- Blown down utility poles.

- Overturned automobiles.

- Some collapsed buildings.

- Fires.

Sturdier buildings (e.g., those with reinforced concrete) will remain standing, lighter commercial and multi-unit residential buildings may have fallen or been rendered structurally unstable, and most single-family houses would be destroyed. Visibility in much of the MDZ could be limited for an hour or more from disruptive effects of the blast wave and building damage. Dust generated by blast-related damage might not be radioactive; however, parts of the MDZ will be contaminated by fallout. As a result, some of the dust will be radioactive and the dust can also contain other hazardous contaminants associated with building material, such as heavy metals and asbestos.

The assessment of building damage suggests that buildings with external wall damage may appear at locations much farther than building with major structural damage. Buildings near the detonation point that have not structurally failed are left as hollow, framed structures with exterior walls missing and likely all lightweight interior construction severely damaged. Most of this damage is contained within the MDZ.

Although the urban environment will create considerable variation of damage, the general extent (range) of the average blast damage estimate is about the same as that for the ideal open field predictions.

The rubble generated from the blast would extend significantly into the MDZ. Depending on city type and the nature of the buildings near the detonation location, piles of debris can vary in size with larger piles nearing 20-30 ft. (6-9 m) near taller buildings.

Emergency response and access to the MDZ will be greatly affected by the substantial rubble as well as crashed or overturned vehicles that will completely block streets and require heavy equipment to clear. Broken water and utility lines are expected in the MDZ, and fires will be encountered. Most people in the MDZ will survive, but many would be injured and will benefit most (compared to casualties in other zones) from urgent medical care (AMA, 2011). Responders in the MDZ should be 
cautious when they begin observing that most buildings are either severely damaged or have collapsed, as that is an indicator they are transitioning from the MDZ to the SDZ.

\section{Light Damage Zone}

The Light Damage Zone (LDZ) is the area that starts just outside of the MDZ and can extend to a distance of about 3 miles at the outer boundary for the 10-kT detonation scenario. Damage in this zone is caused by shocks, similar to those produced by a thunderclap or sonic boom, but with much more force. Although some windows may be broken over 10 miles (16 km) away, injuries associated with flying glass will generally occur within about 3 miles (4.8 km) from ground zero for a 10-kT nuclear explosion and would be associated with overpressures greater than $0.5 \mathrm{psi}$. Damage in the LDZ will be highly variable as shock waves rebound multiple times off buildings, the terrain, and even the atmosphere.

As responders move toward the detonation site from outside the LDZ, windows and doors will be blown in, gutters, window shutters, roofs, and lightly constructed buildings will show increasing damage; litter and rubble will increase and there will be increasing numbers of stalled and crashed automobiles that will make emergency vehicle movement difficult.

More significant structural damage to buildings will indicate to responders that they have entered the MDZ. Much of the LDZ may be nonradioactive; however, responders should be prepared to encounter elevated and potentially hazardous radiation due to fallout. The injuries responders will encounter in the LDZ should be relatively minor, consisting of mostly superficial wounds with the occasional minor crush injuries. Glass and other projectile penetrations are expected to be superficial (i.e., about $1 / 4$ inch in depth) in the torso, limbs, and face. Eyes are particularly vulnerable. As responders proceed inward, they will begin to observe an increasing frequency and severity of injuries from flying glass and debris along with crush, translation, and tumbling injuries.

Glass breakage can be an important long-range, prompt effect. The shockwave that breaks windows travels much more slowly than the bright flash of light. This phenomenon may cause an increased number of injuries if unwarned populations approach windows to investigate the bright flash prior to the shockwave arrival. Most injuries outside the Murrah building during the 1995 Oklahoma City bombing were caused by this phenomenon. Extrapolating from more recent work on conventional explosives, a 10-kT explosion could break certain types of windows (e.g., large, monolithic annealed) located more than 8 miles away (ARA, 2004). NATO medical response planning documents for nuclear detonations state that "... missile injuries will predominate. About half the patients seen will have wounds of their extremities. The thorax, abdomen, and head will be involved about equally." This expectation is consistent with the historical observation that many victims from Nagasaki arriving at field hospitals exhibited glass breakage injuries. 


\section{Blast Effects \\ Severe Damage Zone (half mile radius) \\ Most buildings destroyed, hazards and radiation initially prevents entry into the area; low survival likelihood. \\ Moderate Damage Zone (half to 1 mile radius) \\ Significant building damage and rubble, downed utility poles, overturned automobiles, fires, and many serious injuries. Early medical assistance can significantly improve the number of survivors.

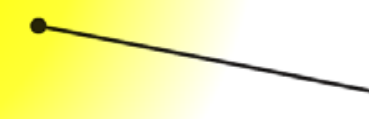 \\ Light Damage Zone ( 1 to 3 mile radius) Windows broken, mostly minor injuries that are highly survivable even without immediate medical care.}

Figure 2: Summary of severe, moderate, and light damage zones and types of damage or injuries likely to be encountered by responders.

\section{Thermal Pulse and Fires}

During the Cold War, fires and firestorms were a major concern because the thermal pulse given off by the detonation can potentially start fires. This effect is diminished for a low-yield detonation, especially at ground level in an urban environment because of (a) considerable urban shielding of thermal radiation and (b) a cooler fireball temperature (relative to an elevated burst). Although a "firestorm" is unlikely given modern construction techniques, numerous small fires will likely start from thermal and blast effects in areas of major building damage. Fires could spread and coalesce if not mitigated. Moreover, the type of structures near the detonation could impact the severity of the fires within the severe and moderate damage zones.

At its largest extent, the fireball from a 10-kT detonation will reach approximately 400 meters in diameter and will include a significant portion of the SDZ. The vertical surface temperature profile around ground zero is more indicative of the potential injuries to a standing population. Significant shadowing occurs in certain section of the city around ground zero.

Building faces and other structures will reach significant temperatures; however the elevated temperatures will quickly subside. With modern, urban construction, it is unlikely that the thermal pulse will create a firestorm; however, numerous small fires will likely start from the combination of thermal and blast effects in areas of major building damage. It is likely that most of the fires will start inside the SDZ and somewhat into the MDZ. However, responders should be aware that fires may spread and coalesce if not mitigated. Additional work is needed to extrapolate how the initiation of urban fires translates to probability of injury in the local populations. 


\section{Flash Blindness}

In addition to ionizing and thermal radiation, a nuclear detonation creates a brilliant flash of light that can cause temporary blindness called flash blindness (or dazzling). Flash blindness can last several seconds to minutes during which useful vision is lost. In an open-field setting, flash blindness can occur up 12 miles away on a clear day with direct line of sight of the fireball. The effect could extend much farther if low clouds were present to reflect light or a detonation were to occur at night.

As with ionizing and thermal radiation, the bright flash of light will be partially blocked by an urban environment and poor atmospheric visibility. Although flash blindness is not expected to cause permanent damage, a sudden loss of vision for drivers could cause numerous traffic accidents and render many roads impassable. MACWG discussions estimated that the range of concern for daytime drivers would be $\sim 8$ miles.

\section{Electromagnetic Pulse}

A nuclear explosion also generates a phenomenon known as Electromagnetic Pulse (EMP) that can negatively impact electronic equipment. However, this issue is primarily a concern for a highaltitude, thermonuclear (high-yield) detonation. For a low-yield, 10-kT, ground-level detonation, the most damaging consequences associated with the pulse are not expected to travel beyond about 1 miles $(<2 \mathrm{~km})$, with some longer-range disruptions of some sensitive equipment occurring out a few miles more (2-4 km). An excellent reference for EMP effects is the 2008 report of the Electromagnetic Pulse Commission (EMPC, 2008).

EMP consequences can be categorized into two types of effect, direct damage and system upset. Direct damage to electronic equipment from EMP is expected to be limited to the SDZ and MDZ. Sporadic "upset" or "latch-up" of equipment may occur in the LDZ and a couple miles beyond, though this temporary condition can be cleared by turning a unit off and then on again (or removing and replacing the battery of portable equipment). Not all equipment within the EMPeffects area will fail, and the frequency of failure will increase the closer to the detonation point the equipment is located.

Because of the effects of EMP and blast wave on critical infrastructure (e.g., power and communication substations), for planning purposes it should be expected that electricity and land line communication would not be functional in the SDZ, MDZ, and LDZ. The disrupting nature of the detonation, including a sudden loss of electrical load on the power grid and the possibility of cascading infrastructure issues may affect the electrical and communication infrastructure of surrounding areas.

Fortunately it is likely that most battery (or hand crank) radios in the MDZ and LDZ will still function. Moreover, emergency radio broadcasts from surrounding areas will be received (EMPC, 2008). Modern vehicles would also likely be unaffected outside of the SDZ and MDZ; however, debris on roadways, traffic accidents caused by flash blindness, and the loss of traffic control systems (one of the more sensitive electronic systems with respect to EMP effect) will make vehicular travel challenging in the LDZ and MDZ. 


\section{Fallout}

A nuclear explosion can produce fallout, which is generated when dust and debris created by the explosion are combined with radioactive fission products and drawn upward into the cloud produced by the detonation. Due to the heat of the explosion, the cloud rapidly climbs through the atmosphere, potentially reaching heights of 5 miles $(8 \mathrm{~km})$ for a 10-kT explosion, and forming a mushroom cloud under ideal conditions. Highly radioactive particles drop back down to earth as the cloud cools.

The gamma radiation emitted from fallout particles can travel large distances. Individuals who are unprotected (e.g., outside), either during the passage of the fallout cloud or after the fallout has deposited, can receive a potentially lethal dose. Away from ground zero, the most dangerous delayed hazard is exposure to ionizing radiation from particles that settle on the ground and building roofs. Radiation levels from these particles drop off quickly with time, with most ( 55\%) of the potential radiation exposure occurring within the first hour after detonation and $\sim 80 \%$ occurring within the first day. Although the fallout pattern is highly dependent on weather conditions, the most dangerous concentrations of fallout particles (i.e., potentially fatal to those outdoors) often occur within 20 miles ( $32 \mathrm{~km}$ ) downwind of ground zero. Fallout particles near the detonation are relatively large and are expected to be clearly visible when they fall. Although these particles can be inhaled, the inhalation hazard is relatively small compared to the dose received by penetrating gamma radiation given off by particles that are on the ground or in the air.

To assist response planning, two different fallout hazard zones have been defined: the Dangerous Fallout Zone (DFZ) (EOP, 2010) and the Hot Zone (NCRP, 2011).

\section{Dangerous Fallout Zone (DFZ)}

The DFZ has the following characteristics for a 10-kT detonation:

- $\quad$ Radiation levels of $10 \mathrm{R} / \mathrm{hr}$ and above.

- Area where exposures leading to acute radiation injury may occur.

- Could reach 10 to 20 miles downwind.

- Decay of radiation causes this zone to shrink after about $1 \mathrm{hr}$.

"The area covered by fallout that impacts responder life-saving operations and/or has acute radiation injury potential to the population is known as the dangerous fallout zone (DFZ). Unlike the LDZ, MDZ, and SDZ, the DFZ is distinguished not by structural damage, but by radiation levels. A radiation exposure rate of $10 \mathrm{R} / \mathrm{h}$ is used to bound this zone, and the DFZ may span across both the LDZ and MDZ.”

Planning Guidance for Response to a Nuclear Detonation (EOP, 2010)

Hot Zone ( $\mathrm{HZ})$

The Hot Zone has the following characteristics for a 10-kT detonation:

- Radiation levels of $0.01 \mathrm{R} / \mathrm{hr}(10 \mathrm{mR} / \mathrm{hr})$ to $10 \mathrm{R} / \mathrm{hr}$.

- Extended stays within the Hot Zone are unlikely to cause any acute radiation effects; however, steps should be taken to control exposure to reduce long-term cancer risk.

- Could extend in numerous directions for 100's of miles. 
- Decay of radiation causes this zone to shrink after about 12 to 24 hours.

- After a week, the Hot Zone will be about the size of the maximum extent of the DFZ (10 to 20 miles).

It is important to note that specific IND impacts will vary with yield, location, and detonation time and no one scenario can cover the range of possible impacts. Planners and responder are expected to adapt the planning guidance to the particular event at hand. It is not recommended that planners or responders plan against the scenario specific numbers directly.

\section{Close-in Exposure Concerns}

Dangerous Fallout Zone (DFZ)

Within 20 miles of the detonation, exposures from fallout can be great enough to cause near-term (within hours) acute radiation syndrome symptoms such as nausea and vomiting.

The highest exposures are expected to occur outdoor individuals would receive radiation exposures great enough $(>800 \mathrm{R})$ that fatalities are likely with or without medical treatment. Further out, outdoor individuals would receive exposures (300 to $800 \mathrm{R}$ ) that would cause near-term health effects (e.g., nausea and vomiting within 4 hours), and some fatalities would be likely without medical treatment. Farther out still, some individuals may experience near-term health effects. Few individuals in areas outside that area are expected to experience near-term health effects (mitigation measures to reduce long-term cancer risk may still be warranted).

The DFZ recommended by national planning guidance encompasses the radioactive fallout hazard areas discussed above. Figure 4 illustrates the maximum DFZ extent and how the DFZ changes over time. In Figure 4, the DFZ is the bright magenta region, the HZ is the pale purple region, and the LDZ, MDZ, and SDZ circles are shown for context. In this illustrative scenario, the DFZ reaches its maximum at 1 hour after detonation (indicated by the dotted line). At later times, the DFZ shrinks in area. 
IND Tech Basis

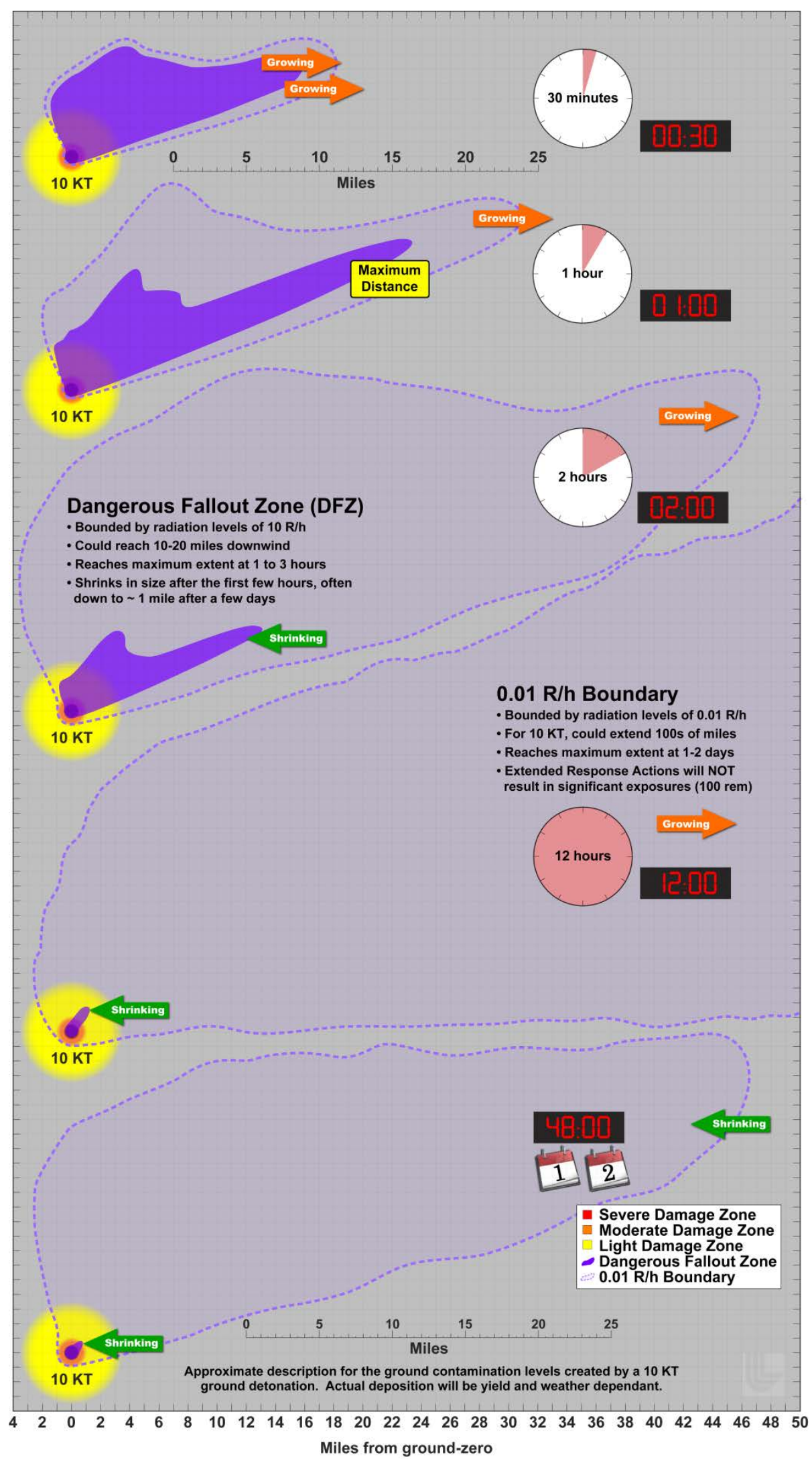

Figure 3: The DFZ (bright magenta area) and HZ (pale purple area) over time. 


\section{Example Fallout I mpacts}

Looking at a location 1 mile from the detonation location would mean that it is on the outer edge of the MDZ. The tall buildings in the area would protect people from potential thermal burns from the fireball.

The blast wave will strike the building several seconds after the flash of light. Although most buildings will be structurally sound, it can be expected that windows in the area will be broken with enough force to cause injury to those behind them. Rooftop equipment and building facades will also collapse into the street, filling urban canyons with potentially $10 \mathrm{~s}$ of feet of metal and glass debris making even walking in the area default.

The blast wave may also kick up dust and debris into the air, obscuring vision within minutes of the detonation. Additional dust may be created when some of the buildings in the severe damage zone (1/2 mile away) also collapse. This material is not the radioactive fallout; however it may keep those in the area from seeing the fallout cloud which arrives within 15 minutes of the detonation.

When the fallout does arrive, it will deposit significant amounts of material in the area. A 10kT nuclear explosion can loft more than 5,000 tons of material into the air and much of the material will come back down locally. This material will be highly radioactive. Outdoor measurements made in the area early after the detonation would find high radiation exposure rates. However, this exposure rate would initially drop off rapidly as the material decays (see Figure 1).

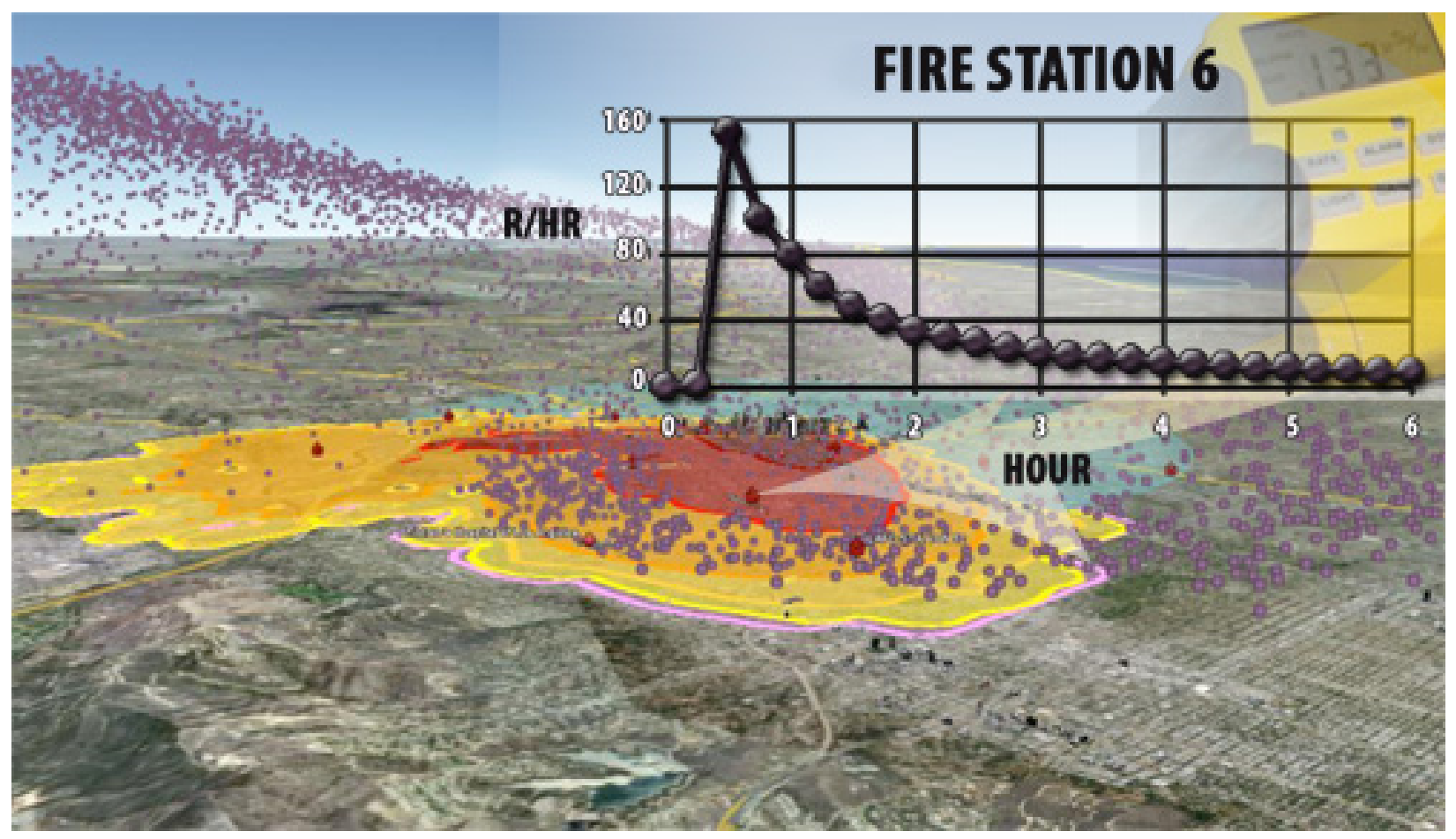

Figure 4: Demonstration of the rapidly changing radiation levels at a point near a nuclear detonation 


\section{Long-Range Exposure Concerns Hot Zone (HZ)}

Beyond 20 miles from the detonation, exposures from fallout are not great enough to cause nearterm (within hours) acute radiation syndrome symptoms such as nausea and vomiting, but are sufficient to increase the risk of cancers in exposed populations. The light orange area in Figure 5 defines the extent of the region where a 4 day outdoor radiation exposure is high enough 5 rem or greater) to warrant protective actions according to the Planning Guidance for Protection and Recovery Following Radiological Dispersal Device (RDD) and Improvised Nuclear Device (IND) Incidents (FEMA, 2008). The yellow area represents radiation levels that are above the EPA and DHS recommendation for shelter or evacuation ( 1 to 5 rem in 4 days). In this region, protective measures should be performed as good protective practice; however, the probability of long term effects (e.g., cancer) is small $(<0.1 \%)$.

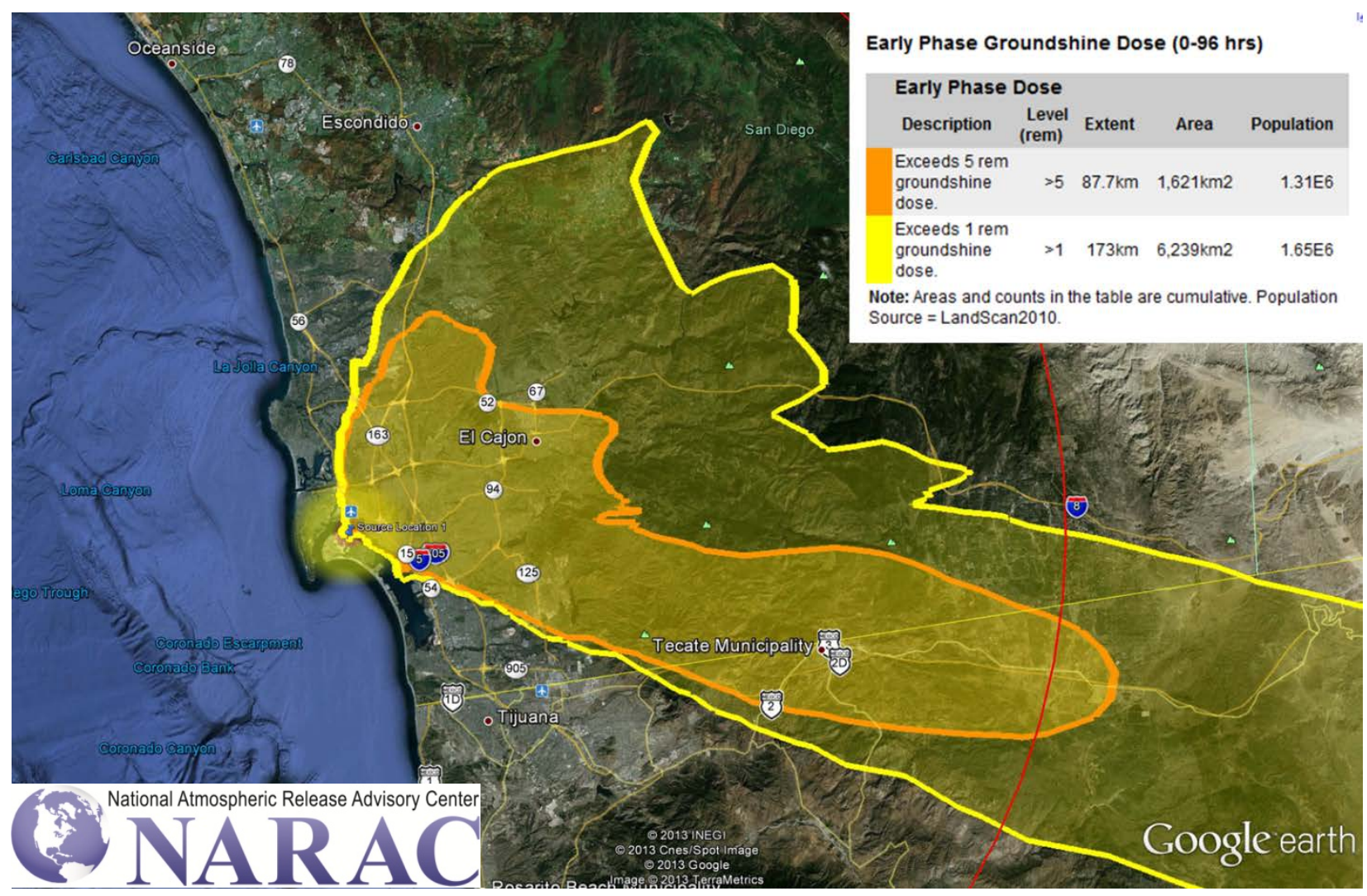

Figure 5: Long-range integrated dose for 4 day outdoor exposure and Protective Action Guidance (PAG).

The Hot Zone (HZ) is defined by NCRP Report 165, Responding to a Radiological or Nuclear Terrorism Incident: A Guide for Decision Makers, as the area where radiation exposure should be minimized through protective equipment and work controls to reduce long-term cancer risk. The $\mathrm{HZ}$ extends much further than the DFZ, and is not predicted to reach its maximum size until at least 6-12 hours after the detonation. The HZ also shrinks after it reaches its maximum and the HZ footprint at 1 week is comparable in size with the DZ footprint at $1 \mathrm{hr}$. 
Hot zone radiation levels range from $0.01 \mathrm{R} / \mathrm{hr}(10 \mathrm{mR} / \mathrm{hr})$ up to $10 \mathrm{R} / \mathrm{hr}$. Response actions in Hot Zones will NOT result in an exposure that could cause an acute radiation effects (i.e., acute radiation syndrome). Caution should still be taken along the edges of the Hot Zone closest to the DFZ to avoid higher exposures and reduce the long-term cancer risk. 


\section{Shelter}

\section{Background}

The exposure to radioactive fallout, and its resulting health impacts, can be significantly reduced by moving inside a sufficiently protective structure (sheltering). Throughout this document, the term "shelter" is used to indicate a location that provides protection from fallout radiation and not a mass care facility for displaced population (e.g., "a Red Cross Shelter”).

Buildings provide protection to their occupants by (a) increasing the distance between fallout particles and those at risk and (b) blocking fallout radiation as it travels through the building. In general:

- The larger the building and heavier the material used in its construction (or contents), the better protection it provides.

- Inner portions of buildings are better protected than outer edges to maximize the distance from fallout particles and the mass between the fallout and individuals.

- $\quad$ Middle floors tend to provide more protection than top or ground floors.

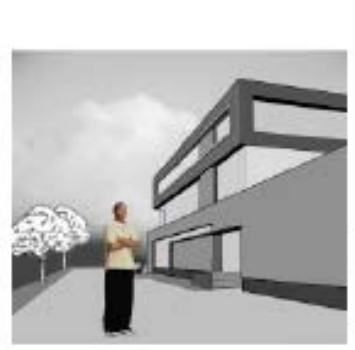

In the open

No protection

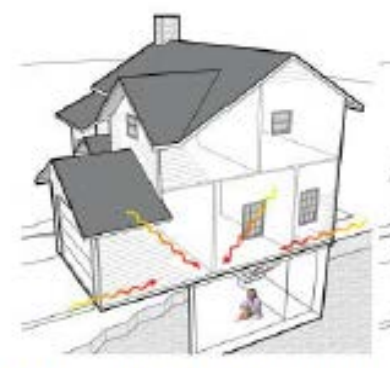

House with a basement Adequate protection
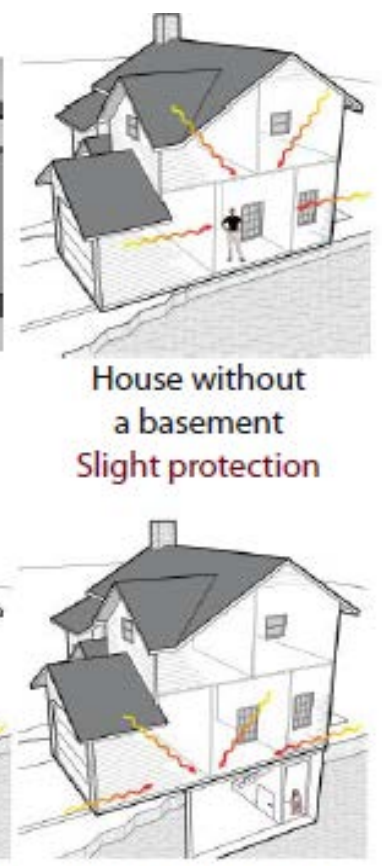

House with a shelter Best protection

Figure 5: Protection can vary depending on location in a building. In this illustration, the best protected location is in the basement against an earthen wall.

Basements are worthy of special note since people sheltering in them have either an entire building (distance + mass) or large amounts of earth (mass) between them and fallout particles. As a result, fully below-ground basements generally provide excellent protection against fallout radiation and are often the best-protected areas of a building. Even typical residential basements that are only $75 \%$ submerged below grade can still offer good protection for occupants positioned near the floor and/or against an earthen wall (see Figure 6).

The protection from radioactive fallout that a building provides is described by its protection factor (PF), which is equal to the ratio of the outside radiation exposure to the inside radiation exposure. As with the SPF of sunscreen, the higher the PF, the more protection from radiation a sheltered person receives compared to an unsheltered person in the same area. Adequate protection, which protects occupants against acute radiation sickness, is defined as a $\mathrm{PF}$ of 10 or greater (EOP, 2010). For consistency, most (but not all) figures in this document use a standard color coding to indicate the shelter quality. This legend and corresponding shelter category labels are provided in Table 4.

Table 4: The color code associated with shelter quality as used in this document. 
During the Cold War, numerous studies examined the shelter efficacy of various buildings and investigated the key factors that determine the protection provided by a given building. Figure 7 shows PF values associated with several building types according to calculations performed during this period. Small, lightly constructed buildings such as wood or vinyl-sided frame houses and offices offer limited protection ( $\mathrm{PF} \approx 3$ ), whereas inner portions of large, multi-story concrete or masonry office buildings can offer excellent protection ( $\mathrm{PF}>100$ ). Basements, in general, offer adequate or better protection $(\mathrm{PF} \geq 10)$. Variations in protection can be considerable within a building. For example, a person on the top floor or an outer, ground-level room in the multi-story office building shown in Figure 30 would have a PF of 10 and would receive $1 / 10$

\begin{tabular}{|c|l|}
\hline $\begin{array}{c}\text { Shelter Quality } \\
\text { Category (PF) }\end{array}$ & \multicolumn{1}{c|}{ Illustrative Buildings } \\
\hline $\begin{array}{c}\text { Poor } \\
(<4)\end{array}$ & $\begin{array}{l}\text { Vehicles and wood-sided single- } \\
\text { story structures without basements, } \\
\text { including homes and strip malls. }\end{array}$ \\
\hline $\begin{array}{c}\text { Inadequate } \\
(\geq 4 \text { to }<10)\end{array}$ & $\begin{array}{l}\text { Stand alone, small footprint, 2-4 } \\
\text { story, lightly constructed homes and } \\
\text { apartment buildings without } \\
\text { basements. }\end{array}$ \\
\hline $\begin{array}{l}\text { Adequate } \\
(\geq 10 \text { to <40) }\end{array}$ & $\begin{array}{l}\text { Residential basements, interior } \\
\text { rooms in the middle of 3+ story } \\
\text { cement or brick wall apartments or } \\
\text { row homes, or the outer areas of } \\
\text { high-rise buildings or mid-rise } \\
\text { buildings with brick/concrete walls. }\end{array}$ \\
\hline $\begin{array}{l}\text { Good } \\
(\geq 40)\end{array}$ & $\begin{array}{l}\text { Large basements or underground } \\
\text { areas and the inner areas of high- } \\
\text { rise buildings or mid-rise buildings } \\
\text { with brick or concrete walls. }\end{array}$ \\
\hline
\end{tabular}
(or 10\%) of the exposure that someone standing outside would receive. Someone in the core of the same building above ground level would be in a room with PF 100.

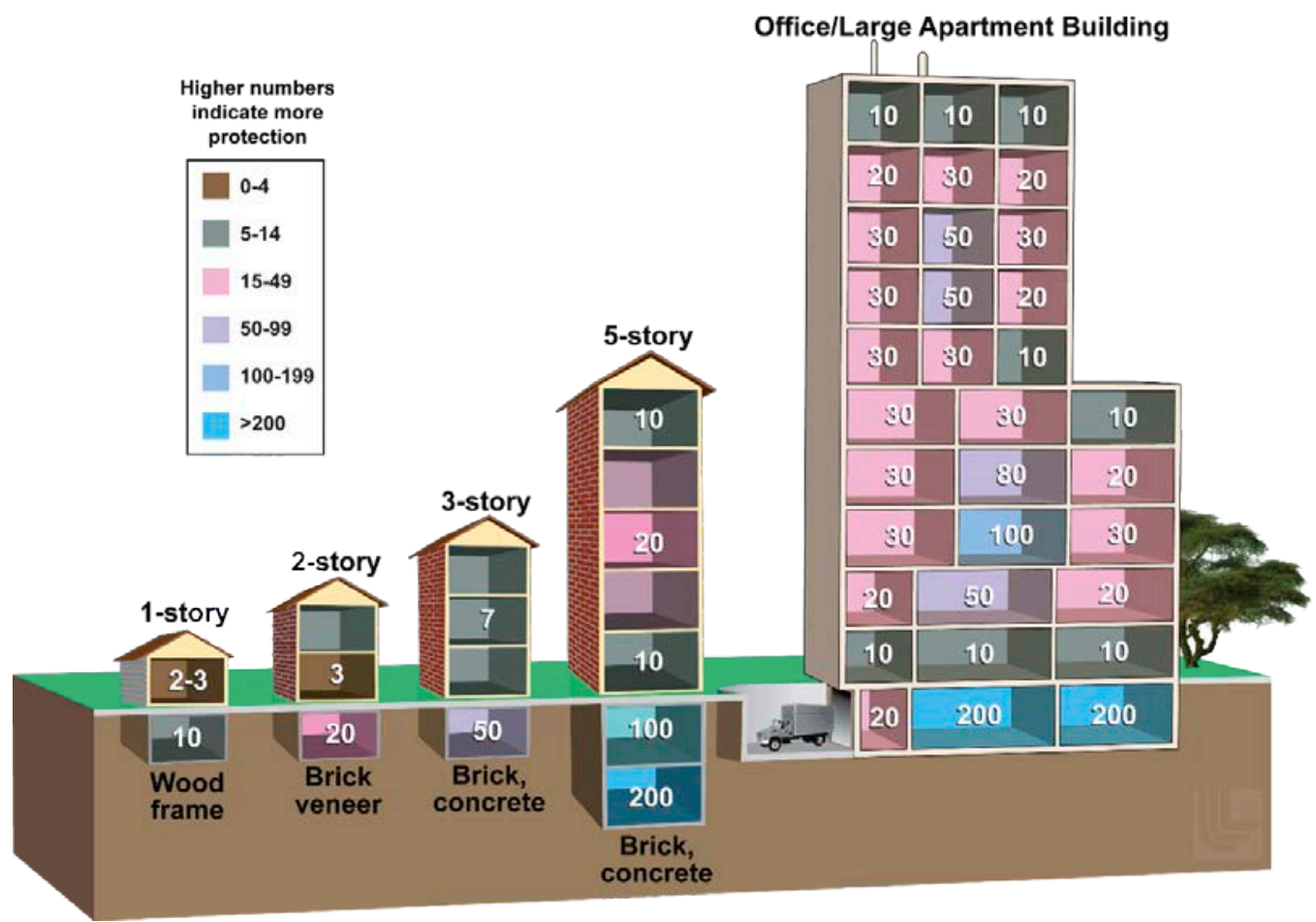

Figure 6: Example protection factors (PFs) for a variety of building types and locations. Adapted from (Ferlic, 1983) and (DCPA, 1973). 
Modern buildings, however, are often constructed differently than those studied in the 1950's through 1970's - raising the question of how much protection modern buildings provide against fallout radiation. Efforts are underway at LLNL, ORNL (Johnson, 2011) and ARA (Bergman, 2011a) to use advanced modeling to improve our understanding of the level of protection modern buildings could provide from fallout radiation. Several key building types have been examined to date and their protection factors are summarized in Table 5.

Table 5: Summary of recent protection factor analysis.

\begin{tabular}{|c|c|c|c|c|}
\hline Structure & $\begin{array}{l}\text { Basement } \\
\text { (PF) }\end{array}$ & $\begin{array}{c}1^{\text {st }} \text { Floor } \\
\text { (PF) }\end{array}$ & $\begin{array}{c}2^{\text {nd }} \text { Floor } \\
\text { (PF) }\end{array}$ & $\begin{array}{c}3^{\text {rd }} \text { Floor } \\
\text { (PF) }\end{array}$ \\
\hline Vehicle & N/A & 1.2 & N/A & N/A \\
\hline Vinyl-sided 2 story home & $22-46$ & $2-4$ & $2-3$ & N/A \\
\hline Brick-sided 2 story homes & $31-62$ & $3-8$ & $3-5$ & N/A \\
\hline Brick-walled 3 story urban row home & $12-31$ & $5-13$ & $8-13$ & $5-11$ \\
\hline Vinyl-sided 3 story apartment & $\mathrm{N} / \mathrm{A}$ & $3-7$ & $2-6$ & $3-5$ \\
\hline Brick-sided 3 story apartment & N/A & $4-11$ & $4-9$ & $4-8$ \\
\hline 3 story office (brick sided concrete walls) & N/A & $8-126$ & $4-43$ & 3-7 \\
\hline
\end{tabular}

\section{Technical Approach}

The LLNL Regional Shelter Analysis is used to evaluate the effectiveness of several shelter strategies. The Regional Shelter Analysis is comprised of two complementary prototype capabilities: PFscreen (building to neighborhood scale) and Svalin (city to national scale). As described below, both capabilities evaluate the efficacy of a shelter strategy by combining the building stock and population databases with estimates of the protection provided by each building type against fallout radiation. The results of either capability can be combined with fallout estimates to estimate indoor radiation exposures.

The shelter strategies considered are:

- Best Local Shelter: people obtain the best protection in the local area, e.g. a nearby concrete hospital;

- Shelter-in-Place: people obtain the best protection available in the building that they are in at the time of detonation, e.g. everyone shelters in the basement; and

- No-Response: people do not move from their location within the building that they are in at the time of detonation, e.g. everyone in an office building remains seated at their desk 


\section{Regional (Svalin Model)}

The prototype Svalin model provides regional-scale shelter quality estimates. The three steps of the process (illustrated in Figure 8) are:

1. Sort regional buildings into one of 36 building types (categorized by construction, basements, and building height).

2. Determine the protection associated with each building type.

3. Combine building protection estimates with estimates of usable building floor area and total number of individuals (workday and nighttime) in each of the 36 different building types.

Step 1

Categorize the available buildings into one of 36 common building types.
Step 2 Assess the building protection for each building type
Step 3

Combine protection estimates with DHS FEMA HAZUS building/population data

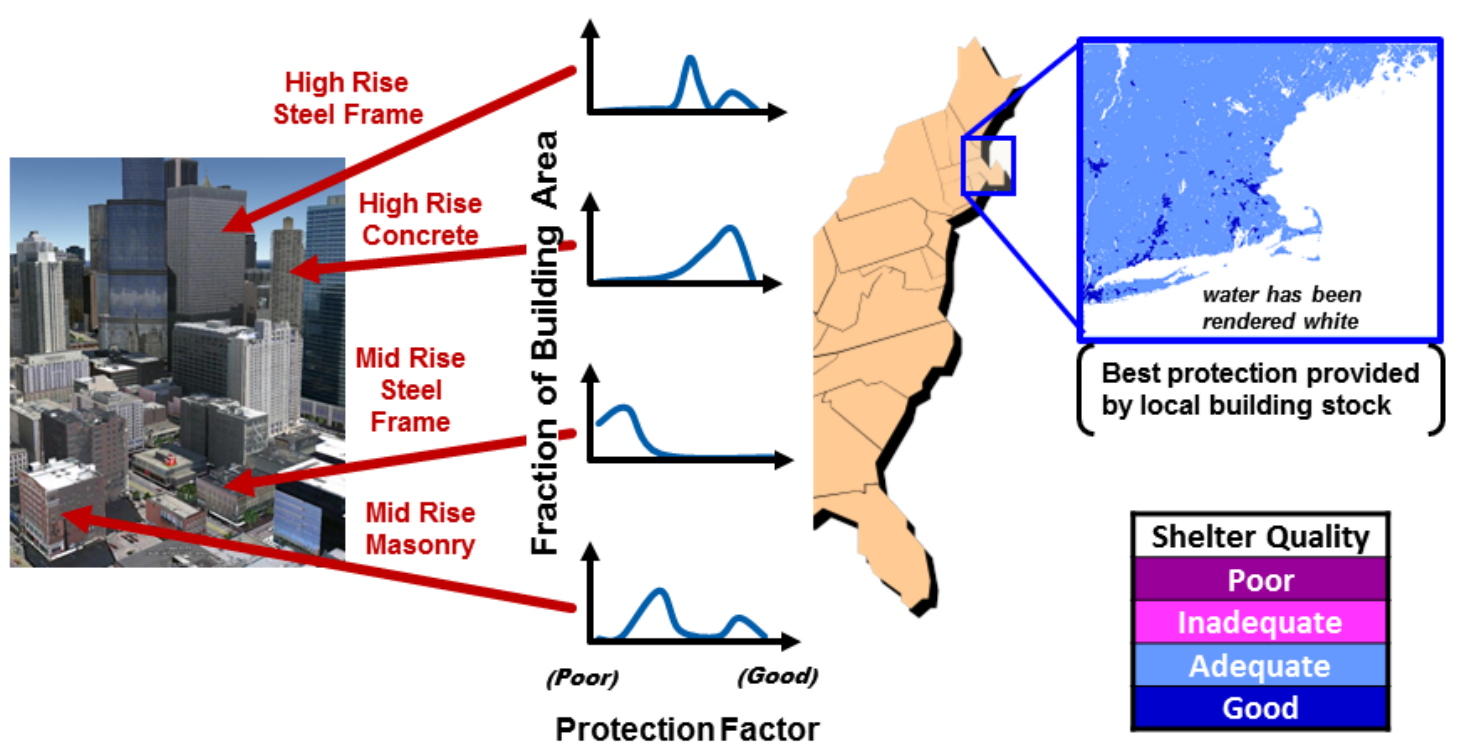

Figure 7: Three-step process by which Svalin estimates regional shelter quality.

Svalin uses the following data:

- $\quad$ DHS (FEMA) HAZUS building datasets. ${ }^{3}$

- Building geometry information available from the National Geospatial-Intelligence Agency (data used under the auspices of the DHS IMAAC program).

- Workday and nighttime population estimates provided by the ORNL LandScan.

- Building protection estimates based on Cold War estimates (Glasstone, 1977).

The Svalin data can be combined with fallout data to not only determine best sheltering locations but also an actual reduction in potential exposure. Combining regional shelter quality with outdoor exposure can provide an estimate of indoor exposures. Figure 8 demonstrates how the area were an outdoor population would receive $>100 \mathrm{R}$ exposure form fallout (left). If that population was inside a nearby building, the

3 For more information on HAZUS, visit: http://www.fema.gov/protecting-our-communities/hazus. 
size of the area where the population would receive more that 100R gamma exposure is dramatically reduced (right image).

Outdoor

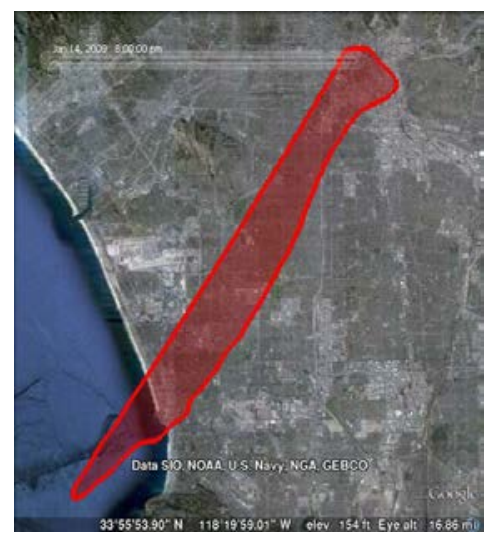

Outdoor Exposure $>100 R$

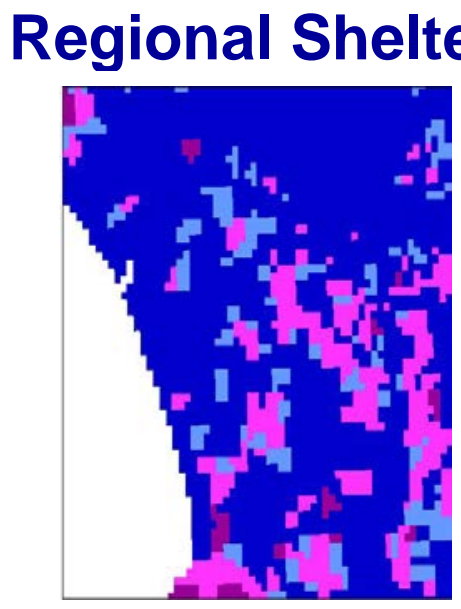

Local Shelter PF
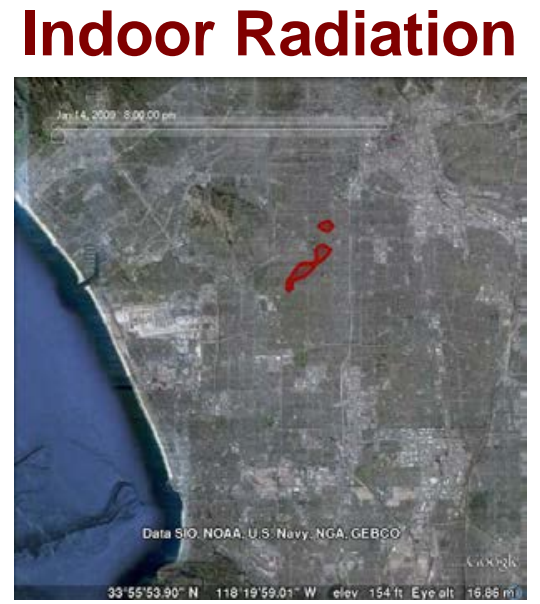

Indoor exposure $>100 R$

Figure 8: Reduction in potential $100 \mathrm{R}$ gamma exposure based on regional shelter quality.

Figure 10 and Figure 11 show the Svalin workday predictions for Los Angeles and San Francisco respectively. During the workday, most individuals in predominately commercial or industrial areas (e.g. the urban core) may already be present at locations with adequate (or better) fallout protection. In contrast, most people in predominately residential areas are likely present in locations with inadequate (or poor) protection (light and dark magenta areas in the left panels). However in both areas, most individuals can improve their shelter quality by seeking the most protective spot in the building (e.g. shelter in place). This action will likely be sufficient to provide almost all individuals with adequate protection against hazardous levels of fallout radiation. For the relatively few individuals in buildings without an adequate shelter location, a best local shelter strategy (moving to the most protective building in a given neighborhood) should be considered as adequate shelter is likely nearby.
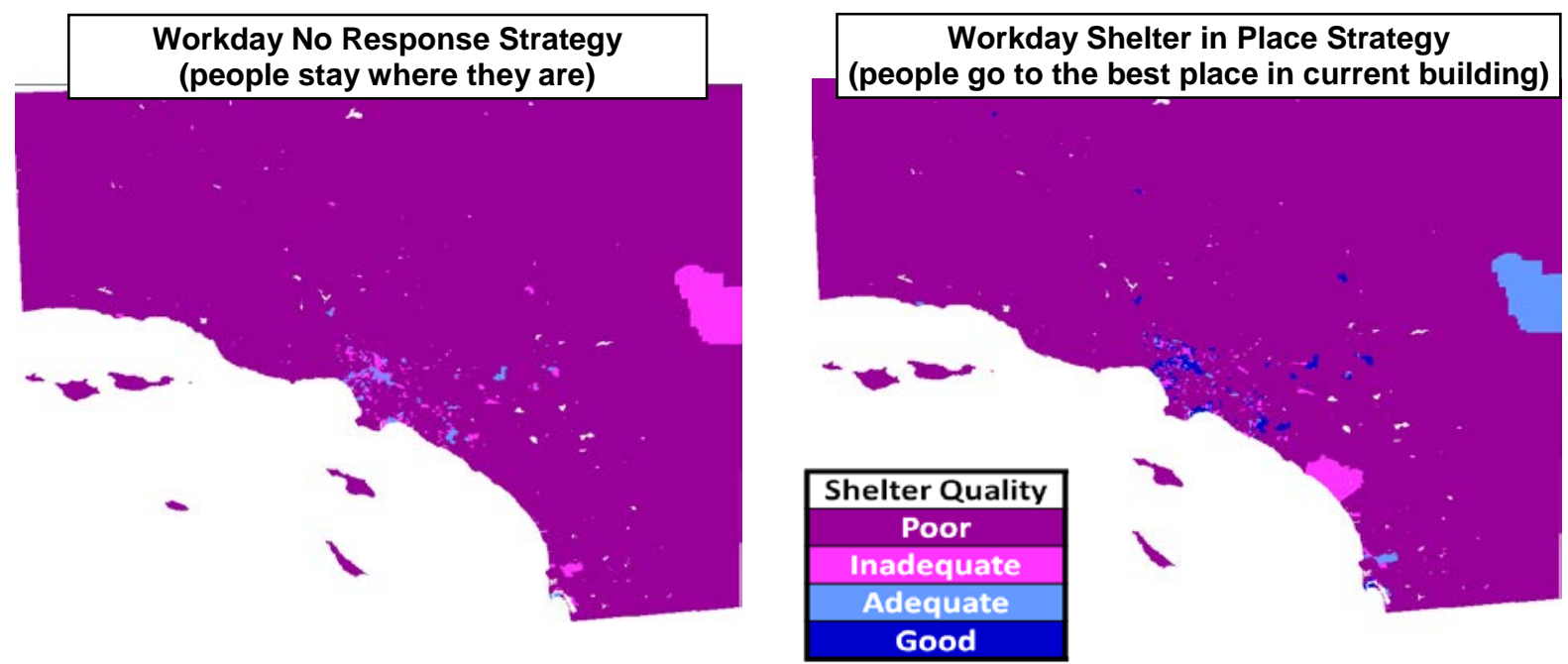

Figure 10: Svalin workday shelter quality maps for San Diego. Region shown is $400 \mathrm{~km} \mathrm{x} 400 \mathbf{k m}$. Water regions are rendered white. 

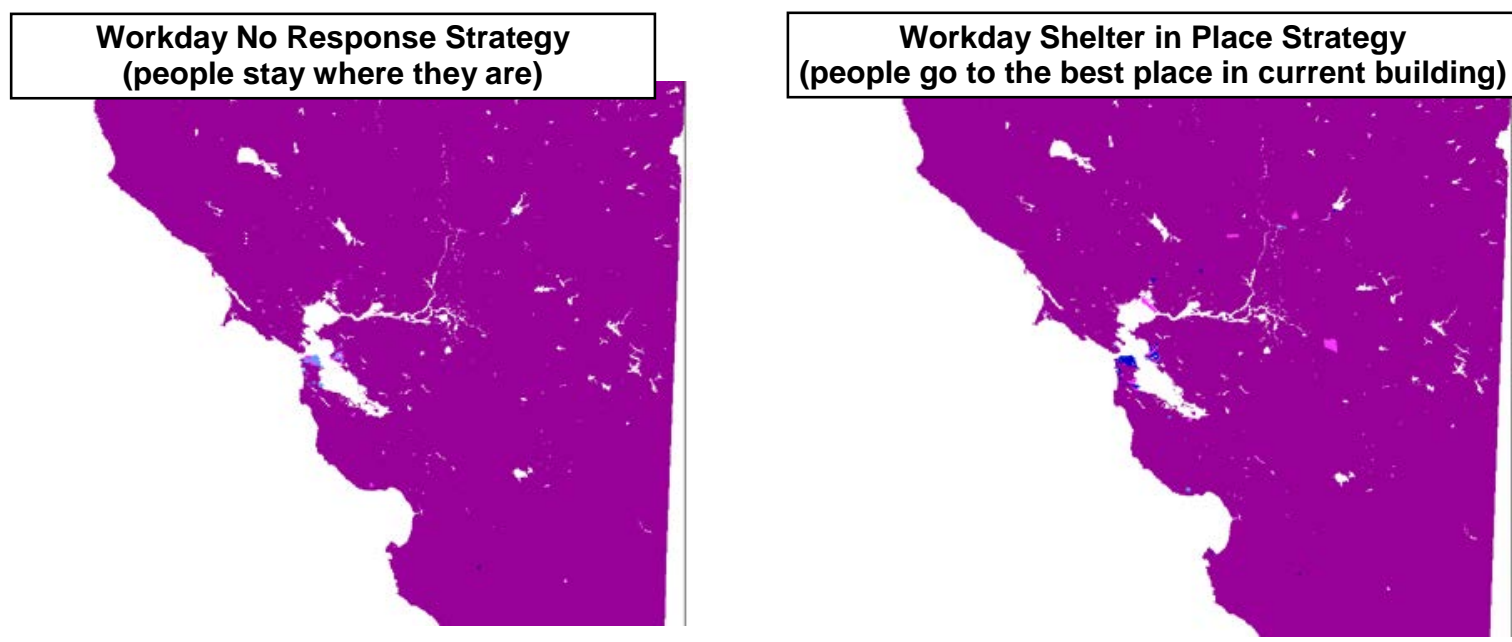

Figure 9: Svalin workday shelter quality maps for San Francisco. Region shown is 400 km x 400 km.Water regions are rendered white.

The nighttime results, shown in Figure 12 and 13 right panels, again suggest that the shelter in place strategy (e.g. core of the building) could likely provide adequate protection to most individuals.
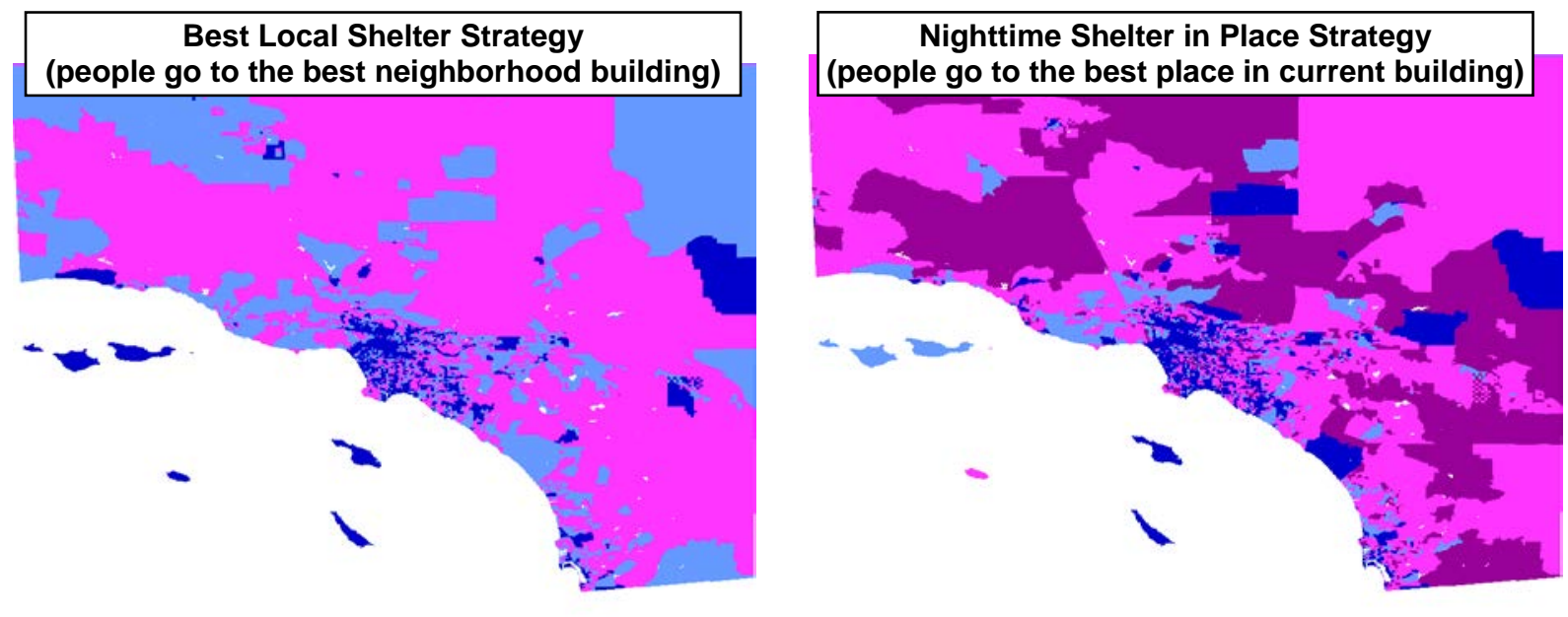

Figure 10: Svalin shelter quality maps for San Diego. Region shown is $500 \mathrm{~km} \mathrm{x} 500 \mathrm{~km}$ centered on the baseline scenario detonation. Water regions are rendered white.

Best Local Shelter Strategy (people go to the best neighborhood building)
Nighttime Shelter in Place Strategy (people go to the best place in current building) 

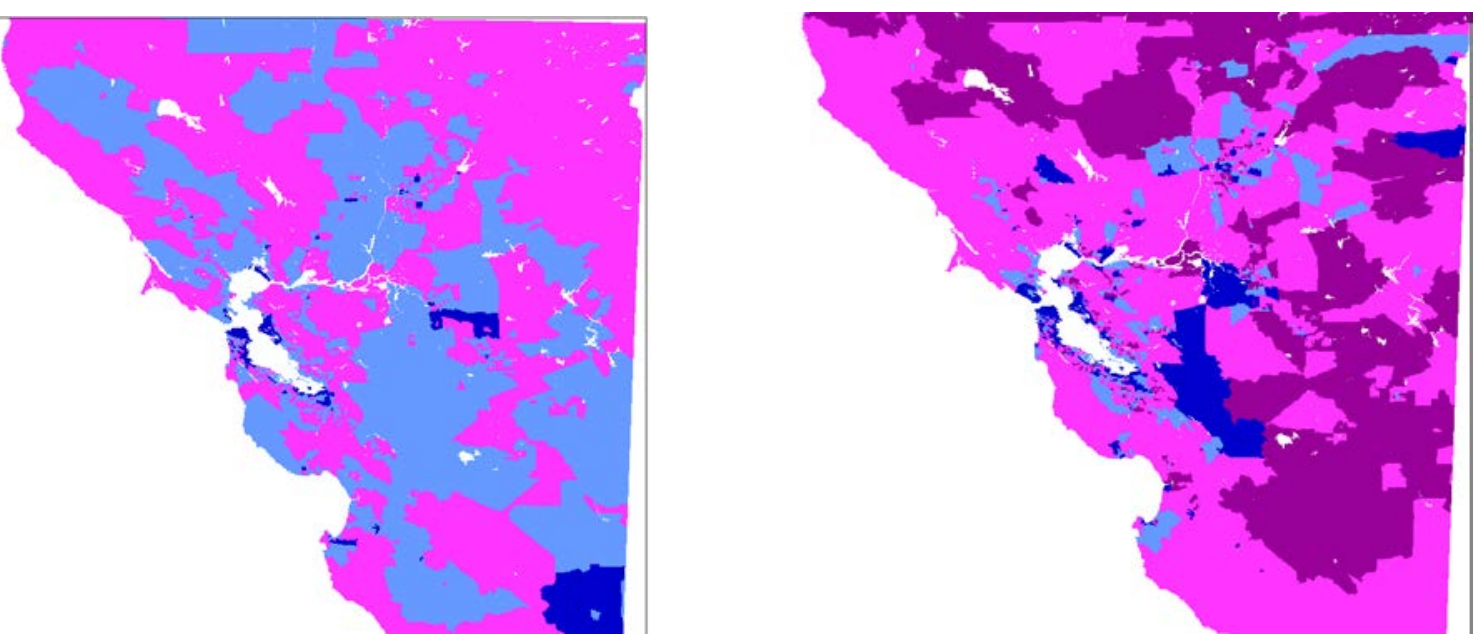

Figure 11: Svalin shelter quality maps for San Francisco. Region shown is $500 \mathrm{~km} x \mathbf{5 0 0} \mathrm{km}$ centered on the baseline scenario detonation. Water regions are rendered white.

\section{The Risks and Benefits of Evacuation}

Eventually, all occupants of the dangerous fallout zone will evacuate. The two important factors that determine when this should be done are (1) the quality of the initial shelter, and (2) the knowledge of suitable and efficient evacuation paths. Several specific considerations in the evacuation decision are:

- Good routes are critical for early evacuees. The choice of a good evacuation route is vital in the first few hours following the detonation when fallout radiation intensity is the greatest. Since information to guide route decisions is unlikely to be available soon after the detonation, any outside transit within the DFZ (which can extend 10-20 miles) will be very risky. Those who need to evacuate due to poor or uninhabitable initial shelters, should minimize their outdoor exposure time. Official evacuation routes established for other hazards (e.g., fire, earthquake, severe storms) may be among the worst route choices, since they can involve extended radial evacuation under the most intense region of the fallout.

- Evacuation route selection becomes less important within a few hours. After only a few hours, fallout radiation intensity decreases sufficiently that evacuation via the ideal route becomes less important. As a result, those who occupy inadequate shelter $(4<\mathrm{PF}<10)$ should consider evacuation beginning approximately 4 to 8 hours following the detonation, even if they have not received information on the location of the most hazardous fallout regions. All evacuating individuals should minimize their outdoor exposure time, particularly in regions close to the detonation point.

- Knowledge of building shelter quality and nearby shelter alternatives can enhance response. In order to make the best shelter transit or evacuation decisions, individuals will need to estimate the quality of their initial shelter and assess the availability of better nearby shelters. However, such individually optimized strategies are less critical than the overall mandate to shelter immediately. For those who find themselves in the most vulnerable environments following the detonation, strategies such as Shelter-dependent-Transit (S-d-T) can reduce their risks, but at the expense of increased complexity in decision making. 


\section{References}

American Academy of Ophthalmology, Ocular Injuries Sustained by Survivors of the Oklahoma City Bombing, ISSN 0161-6420.

(AMA, 2011) American Medical Association (March 2011). Disaster Medicine and Public Health Preparedness, Vol. 4 (supplement 1) (entire edition).

ANSI N13.11 (2001) “Criteria for Testing Personnel Dosimetry Performance.”

ANSI N323A (1997) "Radiation Protection Instrumentation: Test and Calibration, Portable Survey Instruments.”

ANSI N42.17A (1989) "Performance Specifications for Health Physics Instrumentation- Portable Instrumentation for Use in Normal Environmental Conditions.”

ANSI N42.17C (1989) "Performance Specifications for Health Physics Instrumentation-Portable Instrumentation for Use in Extreme Environmental Conditions.”

ANSI N42.20 (2003) "Radiation Protection Instrumentation: Performance Criteria for Active Personnel Radiation Monitors.”

ANSI N42.32 (2006), “American National Standard for Performance Criteria for Alarming Personal Radiation Detectors for Homeland Security.”

ANSI N42.33 (2006), “American National Standard for Portable Radiation Detection Instrumentation for Homeland Security.”

ANSI N42.37 (2006), “American National Standard for Training Requirements for Homeland Security Purposes Using Radiation Detection Instrumentation for Interdiction and Prevention.”

ANSI N42.42 (2007) “American National Standard Data Format Standard for Radiation Detectors Used for Homeland Security.”

(ARA, 2004) Applied Research Associates, Inc., 2004, Injury based glass hazard assessment: range-toeffect curves, Sponsored by US Army Technical Center for Explosives Safety, DACA45-02-D-0004.

(Archibald, 2010) Archibald, E. J. and Buddemeier, B. R. (August 2010). Nuclear Fallout Decision Aid for First Responders, Lawrence Livermore National Laboratory, Livermore, CA, LLNL-TR-449498.

(Bergman, 2011a) Bergman, J. et al. (January 2011). Monte Carlo Modeling of the Radioactive Fallout Protection Factors for an Urban Residence, Applied Research Associates, Inc., ARA-TR-10-SEASSP000521-002.

(Bergman, 2011b) J. Bergman, K. Kramer, B. Sanchez, J. Madrigal, K. Millage, and P. Blake, The Effects of the Urban Environment on the Propagation of Prompt Radiation Emitted from an Improvised Nuclear Device, 56th Annual Meeting of the Health Physics Society, June 29, 2011. 
(Brandt, 2009a) L. D. Brandt and A. S. Yoshimura (June 2009), Analysis of Sheltering and Evacuation Strategies for an Urban Nuclear Detonation Scenario. Sandia National Laboratories Report, SAND20093299.

(Brandt, 2009b) L.D. Brandt, “Mitigation of Nuclear Fallout Risks Through Sheltering and Evacuation”, Paper presented at the Risk Management Topical Session, American Nuclear Society Annual Meeting, Washington, DC, November 18, 2009, Sandia National Laboratories Paper, SAND2009-7367C.

(Brandt, 2009c) Brandt, L. D. and A. S. Yoshimura (November 2009). Nuclear Evacuation Analysis Code (NUEVAC): A Tool for Evaluation of Sheltering and Evacuation Responses Following Urban Nuclear Detonations, Sandia National Laboratories Report,, SAND2009-7507.

(Bhaduri, 2007) B. Bhaduri, E. Bright, P. Coleman, M. Urban, LandScan USA: a high-resolution geospatial and temporal modeling approach for population distribution and dynamics, GeoJournal (2007) 69:103-117.

(Buddemeier, 2009) Buddemeier, B. R. and M. B. Dillon (August 2009). Key Response Planning Factors for the Aftermath of Nuclear Terrorism, Lawrence Livermore National Laboratory, Livermore CA, LLNL-TR-410067.

(Buddemeier, 2010) B. Buddemeier, Reducing the Consequences of a Nuclear Detonation: recent Research, The Bridge Journal, National Academy of Engineering, Summer 2010.

Bursen Z. G. and A. E. Profio 1977 "Structure Shielding in Reactor Accidents” Health Physics v33 pp. 287-299.

(Carter, 2007) Carter, A., May, M., and Perry, W. (2007). “The Day After: Action Following a Nuclear Blast in a U.S. City,” The Washington Quarterly 30:4, 19-32.

(Casagrande, 2011) Casagrande, R., N. Wills, E. Kramer, L. Sumner, M. Mussante, R. Kurinsky, P. McGhee, L. Katz, D. M. Weinstock, and C. N. Coleman (2011). "Using the Model of Resource and Time-Based Triage (MORTT) to Guide Scarce Resource Allocation in the Aftermath of a Nuclear Detonation,” Disaster Medicine and Public Health Preparedness 5(1).

(Crocker, 1966) Crocker, G. R., J. D. O’Connor, and E. C. Freiling (1966). "Physical and Radiochemical Properties of Fallout Particles,” Health Phys. 12, 1099-1104.

(DCPA, 1973) DoD’s Defense Civil Preparedness Agency, Attack Environment Manual, June 1973.

(DHS, 2005) Department of Homeland Security, Homeland Security Presidential Directive 8: National Preparedness.

(DHS, 2010) Department of Homeland Security, DHS Strategy for Improving the National Response and Recovery from an IND Attack, April 2010 (Official Use Only).

(Dey, 2011) T. N Dey and R. J. Bos (2011). Underground Infrastructure Damage for a Chicago Scenario, Los Alamos National Laboratory, LA-UR-11-00566, based on the following work: Hiroyuki Kameda (2000). “Engineering Management of Lifeline Systems Under Earthquake Risk,” Proc. 12th World Conf. 
Earthquake Engineering, 2000; Effects of Nuclear Earth-Penetrator and Other Weapons, Chapter 8 (2005). Committee on the Effects of Nuclear Earth-Penetrator and Other Weapons, National Research Council of the National Academies, The National Academies Press, Washington, DC.

(Eisenhauer C. 1964) An Engineering Method for Calculating Protection Afforded by Structures Against Fallout Radiation National Bureau of Standards Monograph 76.

(EMPC, 2004) Electromagnetic Pulse Commission, Report of the Commission to Assess the Threat to the United States from Electromagnetic Pulse (EMP) Attack, Volume 1: Executive Report. April 2004.

(EMPC, 2008) Electromagnetic Pulse Commission, "Report of the Commission to Assess the Threat to the United States from Electromagnetic Pulse (EMP) Attack Critical National Infrastructures.” April 2008.

(EPA 400-R-92-001) Environmental Protection Agency, Manual of Protective Action Guides and Protective Actions for Nuclear Incidents, May 1992.

(EOP, 2007) Executive Office of the President, Homeland Security Presidential Directive 18: Medical Countermeasures against Weapons of Mass Destruction, January 31, 2007, available at www.dhs.gov/xabout/laws/gc_1219175362551.shtm

(EOP, 2010) Executive Office of the President Homeland Security Council Interagency Policy Coordination subcommittee for Preparedness and Response to Radiological and Nuclear Threats, Planning Guidance for Response to a Nuclear Detonation (June 2010). Office of Science and Technology Policy, available at www.ostp.gov

(Ferlic, 1983) K. P. Ferlic, Armed Forces Radiobiological Research Institute, Fallout: Its Characteristics and Management, AFRRI TR 83-5, 1983.

(FR 73-149) Department of Homeland Security (August 2008). "Protective Action Guides for Radiological Dispersion Device (RDD) and Improvised Nuclear Device (IND) Incidents,” Federal Register 73, No. 149.

(Florig, 2007) Florig, H. K. and B. Fischhoff. “Individuals' Decisions Affecting Radiation Exposure After a Nuclear Explosion,” Health Physics 92(5), 475-483.

(Glasstone, 1977) S. Glasstone and P. J. Dolan, 1977, The Effects of Nuclear Weapons (third edition). Washington, D.C.: U.S. Government Printing Office Hiroyuki Kameda (2000). "Engineering Management of Lifeline Systems Under Earthquake Risk,” Proc. 12th World Conf. Earthquake Engineering.

(Johnson, 2010) Johnson, J. O. et al. (April 2010). Assessment of Building Protection Factors for Fallout Radiation due to an IND Urban Detonation, Oak Ridge National Laboratory, Oak Ridge TN. For more information contact the author at johnsonjo@ornl.gov.

(Hrdina, 2009). The “RTR” Medical Response System for Nuclear and Radiological Mass-Casualty Incidents: A Functional TRiage-TReatment-TRansport Medical Response Model. 
ICRP Publication 96 (2006) Protecting People Against Radiation Exposure in the Event of a Radiological Attack.

(Li, 2012) Li, Andy, Brownstone Residence Protection Factor Calculation, Applied Research Associates, Inc., May 2012, ARA/HS-TN-12-008-A.

(Marrs, 2007) Marrs, R. E., W. C. Moss, and B. Whitlock (June 7, 2007). Thermal Radiation from Nuclear Detonations in Urban Environments, Lawrence Livermore National Laboratory, Livermore, CA, UCRL-TR-231593.

(Mines, 2000) Michael Mines, MD, DVM, et. al., Ocular Injuries Sustained by Survivors of the Oklahoma City Bombing, American Academy of Ophthalmology, v.107, p.837-47, ISSN 0161-6420, 2000.

(NAE, 2005) Committee on the Effects of Nuclear Earth-Penetrator and Other Weapons (2005). Effects of Nuclear Earth-Penetrator and Other Weapons, Chapter 8, National Research Council of the National Academies, The National Academies Press, Washington, D.C.

(NAE, 2010) National Academy of Engineering of the National Academies (summer 2010). The Bridge 40(2) (entire edition).

(Nasstrom, 2011) J. S. Nasstrom, K. T. Foster, P. Goldstein, M. B. Dillon, N. G. Wimer, S. Homann, and G. Sugiyama, Advances in Modeling Radiation Dispersal Device and Nuclear Detonation Effects, ANS EPRRSD, 13th Robotics and Remote Systems for Hazardous Environments, 11th Emergency Preparedness and Response, Knoxville, TN, August 7-10, 2011, American Nuclear Society, LaGrange Park, IL (2011), LLNL-CONF-486512.

(NATO, 1996) NATO, NATO Handbook on the Medical Aspects of NBC Defensive Operations (Part I Nuclear). Departments of the Army, Navy, and Air Force: Washington, DC.

(NCRP, 1982) National Council on Radiation Protection and Measurements (NCRP, 1982). The Control of Exposure of the Public to Ionizing Radiation in the Event of Accident or Attack, NCRP Symposium Proceedings (Session B, Topic 4).

(NCRP, 2001) National Council on Radiation Protection and Measurement. Management of Terrorist Events Involving Radioactive Material, Report No. 138.

(NCRP, 2011) National Council on Radiation Protection and Measurement (NCRP, February 2011). Responding to a Radiological or Nuclear Terrorism Incident: A Guide for Decision Makers, Report No, 165.

(NFPA 472 2008) Standard for Competence of Responders to Hazardous Materials/Weapons of Mass Destruction Incidents.

(Reed, 1992) J. W. Reed, Analysis of the Accidental Explosion at PEPCON, Henderson, Nevada, on May 4, 1988, Sandia National Laboratories (SAND88-2902), Propellants, Explosives, and Pyrotechnics, 17, 88-95 (1992). 
Spencer, L.V. 1962 Structure Shielding Against Fallout Radiation from Nuclear Weapons National Bureau of Standards Monograph 42.

(UPMC,2011) University of Pittsburg Medical Center, Center for Biosecurity. The Rad Resilient Cities Project; available at www.radresilientcity.org (accessed October 13, 2011). 